\title{
Raisanberine protected pulmonary arterial rings and cardiac myocytes of rats against hypoxia injury by suppressing NADPH oxidase and calcium influx
}

\author{
Jie GAO\#, Yi-qun TANG\#, De-zai DAI*, Yu-si CHENG, Guo-lin ZHANG, Can ZHANG, Yin DAI \\ Research Division of Pharmacology, China Pharmaceutical University, Nanjing 210009, China
}

\begin{abstract}
Aim: To investigate the protection of pulmonary arterial rings and cardiac myocytes of rats by raisanberine (RS), a derivative of berberine, against hypoxia injury and to elucidate the action mechanisms.

Methods: Adult SD rats were exposed to intermittent hypoxia for $17 \mathrm{~d}$ or $28 \mathrm{~d}$. The pulmonary arterial rings were isolated and vascular activity was measured using a transducer and computer-aided system. The difference in the tension produced by phenylephrine in the presence and absence of $L$-nitroarginine $(10 \mu \mathrm{mol} / \mathrm{L})$ was referred to as the NO bioavailability; the maximum release of NO was assessed by the ratio of the maximal dilatation caused by ACh to those caused by sodium nitroprusside. After the lungs were fixed, the internal and the external diameters of the pulmonary arterioles were measured using a graphic analysis system. Cultured cardiac myocytes from neonatal rats were exposed to $\mathrm{H}_{2} \mathrm{O}_{2}(10 \mu \mathrm{mol} / \mathrm{L})$ to mimic hypoxia injury. ROS generation and [Ca $\left.{ }^{2+}\right]_{\mathrm{i}}$ level in the myocytes were measured using DHE and Fluo-3 fluorescence, respectively.

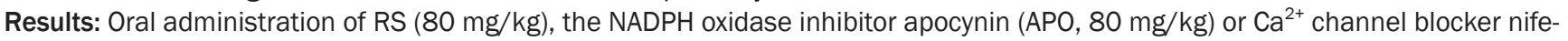
dipine (Nif, $10 \mathrm{mg} / \mathrm{kg}$,) significantly alleviated the abnormal increase in the vasoconstriction force and endothelium-related vasodilatation induced by the intermittent hypoxia. The intermittent hypoxia markedly decreased the NO bioavailability and maximal NO release from pulmonary arterial rings, which were reversed by APO or RS administration. However, RS administration did not affect the NO bioavailability and maximal NO release from pulmonary arterial rings of normal rats. RS, Nif or APO administration significantly attenuated the pulmonary arteriole remodeling. Treatment of cultured cardiac myocytes with RS ( $10 \mu \mathrm{mol} / \mathrm{L})$ suppressed the ROS generation and $\left[\mathrm{Ca}^{2+}\right]_{i}$ increase induced by $\mathrm{H}_{2} \mathrm{O}_{2}$, which were comparable to those caused by APO $(10 \mu \mathrm{mol} / \mathrm{L})$ or Nif $(0.1 \mu \mathrm{mol} / \mathrm{L})$.

Conclusion: Raisanberine relieved hypoxic/oxidant insults to the pulmonary artery and cardiac myocytes of rats by suppressing activated NADPH oxidase and increased calcium influx.
\end{abstract}

Keywords: raisanberin; apocynin; nifedipine; hypoxia; pulmonary artery; cardiac myocytes; NADPH oxidase; calcium influx

Acta Pharmacologica Sinica (2012) 33: 625-634; doi: 10.1038/aps.2012.7

\section{Introduction}

Pulmonary arterial hypertension (PAH) caused by hypoxia is characterized by a progressive elevation of the resistance of the pulmonary arterial system and insults to the heart; hypoxia causes oxidant lesions that adversely affect cardiac myocytes, contributing in part to right heart failure and increased mortality ${ }^{[1]}$. The pulmonary vascular endothelium is abnormal after exposure to hypoxia, elevating the pulmonary arterial pressure by enhancing constriction and reducing dilatative activity due to compromised NO availability. Extensive research demonstrates that an excess of ET-1 (endothelin-1) is

\footnotetext{
\# These authors contributed equally to this work.

* To whom correspondence should be addressed.

E-mail dezaidai@vip.sina.com

Received 2011-08-18 Accepted 2012-01-14
}

actively involved in the pathogenesis of PAH and that PAH can be reversed by ET receptor-blocking agents ${ }^{[2,3]}$.

Endothelium-dependent relaxation depends on the biosynthesis and release of $\mathrm{NO}$ by endothelial nitric oxide synthase (eNOS) in the vascular endothelia. The activity of eNOS generates both $\mathrm{NO}$ and superoxide $\left(\mathrm{O}_{2}^{-}\right)$, which are key mediators of cellular signaling in regulating vascular activity ${ }^{[4]}$. Vascular relaxation by $\mathrm{NO}$ is counteracted by activated $\mathrm{ET}_{\mathrm{A}}$, resulting in compromised NO bioavailability and a decrease in the eNOS activity, which are related to an excess of reactive oxygen species (ROS), and is likely attributable to activated NADPH oxidase. ET-1 is an inducer of NADPH oxidase mainly through $\mathrm{ET}_{\mathrm{A}}{ }^{[5]}$, and the biosynthesis and release of the vascular dilating substance, $\mathrm{NO}$, in vascular endothelia are seriously affected by oxidative stress ${ }^{[6]}$. The pathogenesis of hypoxic PAH can be characterized by an activated ET pathway, which was relieved 
by the ET antagonists CPU0213 ${ }^{[7]}$ and CPU86017 $7^{[8]}$, and its isomers ${ }^{[9]}$ by reducing $\mathrm{ET}_{\mathrm{A}}$ expression in the pulmonary vasculature.

NADPH oxidase-derived ROS may play a major role in the pathology of hypoxia-induced $\mathrm{PAH}^{[10]}$. NADPH oxidase belongs to a family of proteins that consist of two groups of subunits, catalytic components, NOX1, gp91 $1^{\text {phox }}$ (NOX2), and NOX4, and modulating components, $\mathrm{p} 22^{\text {phox }}, \mathrm{p} 47^{\text {phox }}$, and p $67^{\text {phox }}$, which localize separately either at the membrane or in the cytosol ${ }^{[11]}$. Decreased vasorelaxation is mediated by an upregulated ET system, as found in hypoxic pulmonary arteries $^{[12]}$ and in aortic rings from diabetic rats ${ }^{[13]}$, which are likely the consequence of activated NADPH oxidase enzymes. The insults due to hypoxia are mainly mediated by an increased generation of ROS, and the activation of $\mathrm{ET}_{\mathrm{A}}$ is caused by either hypoxia ${ }^{[7,8]}$ or incubation with $\mathrm{H}_{2} \mathrm{O}_{2}{ }^{[14]}$. In fact, hypoxia activates NADPH oxidase, causing an increase in ROS production, which stimulates the ET system. The accumulated data suggest that the activity of $\mathrm{ET}_{\mathrm{A}}$ is at least in part mediated by activated NADPH oxidase ${ }^{[6]}$ and that an increase in calcium influx may be initiated by $\mathrm{H}_{2} \mathrm{O}_{2}$ (ROS) as a consequence of hypoxia: an involvement of NADPH oxidase may be critically implicated in the pathology of hypoxia-induced abnormalities of the pulmonary vasculature and cardiac myocytes.

Raisanberine (RS compound, an isomer of CPU86017: $[+]-7 R, 13 a S-p$-chloro-benzyl-tetra-hydro-berberine chloride) is active in reversing the abnormal expression of the ET system in pulmonary artery hypertension in rats ${ }^{[15,16]}$. In our previous study, RS improved the remodeling of the pulmonary arterioles ${ }^{[9]}$ and blocked calcium influx through L-type calcium channels ${ }^{[17]}$; however, it remained uncertain whether raisanberine was capable of reducing ROS generation through the suppression of NADPH oxidase in the pulmonary arterial vasculature and cardiac myocytes.

We hypothesized that an activated NADPH oxidase may be caused by hypoxia and induce abnormal pulmonary arterial activity and intracellular free calcium in cardiac myocytes. $\mathrm{H}_{2} \mathrm{O}_{2}$-induced abnormalities of intracellular calcium in cardiac myocytes mimic the insults due to hypoxia and are likely due to an activation of NADPH oxidase. The aim of our research was to verify this hypothesis by employing apocynin, an inhibitor of NADPH oxidase, the calcium channel blocker nifedipine, and RS to test their efficacy in alleviating the hypoxiarelated abnormalities of pulmonary arteries and cardiac myocytes.

\section{Materials and methods \\ Experimental animals}

Male Sprague-Dawley rats, weighing 220-250 g, were purchased from the Experimental Animal Center of Zhejiang Province, Hangzhou. License No: SCXK (Zhe) 20080033. The procedures involving experimental animals were conducted by personnel trained according to the Experimental Animal Handling Act instituted by the Science-Technology Bureau of Jiangsu Province, China.

\section{Drugs and reagents}

Raisanberine (CPU86017-RS, RS) was synthesized and provided by the Department of Medicinal Chemistry, China Pharmaceutical University, Lot 20090301. Nifedipine (Nif) (10 mg/ tablets) was obtained from Changzhou Kangpu Pharmaceutical Co, Ltd, Lot 0910004. Apocynin (APO) (white crystalline powder; Lot 122F20340) was obtained from Sigma-Aldrich Chemie GmbH, Steinheim, Germany. DHE and Fluo-3/AM were purchased from Sigma-Aldrich, St Louis, MO, USA.

\section{Exposure to intermittent hypoxia}

A total of 110 rats were randomly divided into two experiments: (1) in Exp 1, 4 groups $(n=6)$ were exposed to intermittent hypoxia for $17 \mathrm{~d}$, and in the last $12 \mathrm{~d}$, APO $80 \mathrm{mg} / \mathrm{kg}$ and RS $80 \mathrm{mg} / \mathrm{kg}$ was administered (po); in Exp 2, hypoxic rats were untreated (Hyp) or treated $(\mathrm{mg} / \mathrm{kg}, \mathrm{po})$ with Nif (10), APO (80), RS low dose (RSL, 20), RS medium dose (RSM, $40)$, or RS high dose (RSH, 80), and normal rats were either untreated (Nor) or received the RS high dose (N+RS, 80); these 8 groups $(n=10)$ received the treatments in the last $14 \mathrm{~d}$ of the experiment. According to a previous report ${ }^{[8]}$ we used a hypoxia chamber in which the oxygen fraction was maintained at $10 \% \pm 0.5 \%$ by controlling the $\mathrm{N}_{2}$ flow into the chamber. The water vapor and carbon dioxide were removed by placing anhydrous calcium chloride and sodium lime in the chamber. The rats were kept in the hypoxic chamber for $8 \mathrm{~h}$ per day for 17 and $28 \mathrm{~d}$ for $\operatorname{Exp} 1$ and 2, respectively, except for the Nor and $\mathrm{N}+\mathrm{RS}$ groups. The rats in the Nor, Hyp and N+RS groups were administered the same volume of $0.5 \%$ CMC-Na.

\section{Vascular activity of isolated pulmonary arterial rings}

The rats were anesthetized with urethane $1.5 \mathrm{~g}$, ip, the chest was opened, and the pulmonary artery was rapidly harvested and placed in cold $\mathrm{K}-\mathrm{H}$ solution, containing the following (in mmol/L): $\mathrm{NaCl} 119, \mathrm{NaHCO}_{3} 25, \mathrm{KCl} 4.6, \mathrm{KH}_{2} \mathrm{PO}_{4}$ 1.2, $\mathrm{MgCl}_{2} 1.2, \mathrm{CaCl}_{2} 2.5$, and glucose 11, and saturated with $95 \%$ $\mathrm{O}_{2}+5 \% \mathrm{CO}_{2}$ (2 bubbles/s). The connective tissue surrounding the artery was removed, and the pulmonary artery was cut into rings of $2 \mathrm{~mm}$ in width. The rings were fixed by a triangular steel ring to the bottom of a $3 \mathrm{~mL}$ organ bath and connected to a transducer and a computer-aided system for real time recordings, as previous reported ${ }^{[8]}$. The resting tension baseline of the vascular ring was loaded to $0.6-0.7 \mathrm{~g}$. After stabilization for $2 \mathrm{~h}$ with 3 tests of norepinephrine at $1 \mu \mathrm{mol} / \mathrm{L}$, Phe (phenylephrine, 3, 30, and $300 \mathrm{nmol} / \mathrm{L}$ ) was added in sequence for recordings of the developed tension of the vascular rings. After reaching the plateau, the isolated vascular rings were dilated by adding ACh (acetylcholine, 0.01, 0.1, 1, and $10 \mu \mathrm{mol} / \mathrm{L}$ ), and the vascular rings were dilated further by adding SNP (sodium nitroprusside, $10 \mu \mathrm{mol} / \mathrm{L}$ ) until reaching the maximum relaxation. After incubating the vascular rings for $15 \mathrm{~min}$ with L-NA (L-nitroarginine, an inhibitor of eNOS, $10 \mu \mathrm{mol} / \mathrm{L}$ ), the testing of vascular contraction and relaxation was repeated. The difference in the tension produced by Phe in the presence and absence of L-NA was taken as the functional assessment of the NO released from the vascular 
endothelium and referred to as the NO bioavailability; the maximum release of $\mathrm{NO}$ was assessed by using a functional approach. The relaxation caused by ACh is endothelium dependent and can be considered to represent the maximum release of NO. The ACh-induced relaxation was compared to those caused by SNP which was taken as $100 \%$, therefore, the ability of the pulmonary artery to release NO could be calculated $^{[13,18]}$.

\section{Morphological analysis of pulmonary arterioles}

The lungs were fixed with neutral formalin, embedded in paraffin, and sliced into 4- $\mu$ m-thick sections (HE stain, $\times 400$ ). The length of the internal (ID) and the external diameter (ED) of the pulmonary arterioles were measured using a graphic analysis system (IMAGE-PROPLUS [Media Cybernetics, Silver Spring, MD] $)^{[9]}$. The pulmonary arterioles with EDs less than $150 \mu \mathrm{m}$ were selected, and 10 visual fields for each slide were randomly chosen.

The wall thickness (WT) percentage was calculated as follows:

$$
\mathrm{WT}(\%)=100 \times 0.5 \times([\mathrm{ED}-\mathrm{ID}] / \mathrm{ED})^{[9]}
$$

\section{ROS in cultured cardiac myocytes}

The cardiac myocytes from neonatal rats $(48 \mathrm{~h})$ were employed for assessing the fluorescence intensity of ROS when stained with DHE (dihydroethidium), as based on a previous report ${ }^{[19]}$; the cell density was adjusted to $6 \times 10^{5} / \mathrm{mL}$ and diluted 3 -fold. These cells were then divided into 7 groups: normal (Nor); hypoxic (Hyp, $\mathrm{H}_{2} \mathrm{O}_{2} 10 \mu \mathrm{mol} / \mathrm{L}$ was used to mimic an increase in the ROS due to hypoxia exposure); nifedipine (Nif, 0.1 $\mu \mathrm{mol} / \mathrm{L})$; apocynin (APO, $10 \mu \mathrm{mol} / \mathrm{L}) ; \mathrm{RSL}$ (RS, $1 \mu \mathrm{mol} / \mathrm{L})$; RSM (RS, $3 \mu \mathrm{mol} / \mathrm{L})$; and RSH (RS, $10 \mu \mathrm{mol} / \mathrm{L})$. The cardiac myocytes were washed with fresh Tyrode's solution, incubated with DHE (10 $\mathrm{mmol} / \mathrm{L})$ under darkness, and then observed using a fluorescence microscope $(\times 100$, OLYMPUS, IX71). The fluorescence intensity was evaluated using ImagePro Plus 6 and compared among the groups.

\section{$\left[\mathrm{Ca}^{2+}\right]_{\mathrm{i}}$ in cultured cardiac myocytes}

The primary cardiac cells isolated from adult rats were employed, and the measurements of $\left[\mathrm{Ca}^{2+}\right]_{\mathrm{i}}$ were obtained by incubation with fluorescent Fluo-3/AM at $10 \mu \mathrm{mol} / \mathrm{L}$; the cardiac myocytes were stimulated using electric field stimulation, according to previous reports ${ }^{[20,21]}$. The cardiac myocytes were divided into 7 groups: Nor (normal), Hyp (hypoxic injury was mimicked by incubation with $\mathrm{H}_{2} \mathrm{O}_{2} 10 \mu \mathrm{mol} / \mathrm{L}$ ), Nif (nifedipine, $0.1 \mu \mathrm{mol} / \mathrm{L})$, APO (apocynin, $10 \mu \mathrm{mol} / \mathrm{L})$, RSL (0.1 $\mu \mathrm{mol} / \mathrm{L}), \mathrm{RSM}(1 \mu \mathrm{mol} / \mathrm{L})$ and RSH $(10 \mu \mathrm{mol} / \mathrm{L})$. The incubation with Fluo-3 was performed in the dark, and the fluorescent images of the cells were observed using a fluorescence microscope while the cells were beating due to stimulation with $0.5 \mathrm{~Hz}, 40 \mathrm{~V}$ electric-field stimulation. The fluorescence intensity was measured and recorded using Image-Pro Plus 6. After adding $\mathrm{CaCl}_{2}(10 \mathrm{mmol} / \mathrm{L})$ and A23187 (5 mmol/L) into Tyrode's solution, the fluorescence intensity was abruptly increased to reach the maximum and recorded as the $F_{\max }$ value. After $\mathrm{MnCl}_{2}(5 \mathrm{mmol} / \mathrm{L})$ and A23187 (5 mmol/L) were added, the fluorescence intensity gradually decreased to a certain level and remained unchanged; this was recorded and referred to as $F_{\min }$. The levels of $\left[\mathrm{Ca}^{2+}\right]_{i}$ were calculated according to the following formula: $\left[\mathrm{Ca}^{2+}\right]_{\mathrm{i}}=K_{\mathrm{d}} \times\left(F-F_{\min }\right) /\left(F_{\max }\right.$ $-F)$. The peak (systolic) and trough (diastolic) concentrations of $\left[\mathrm{Ca}^{2+}\right]_{\mathrm{i}}$ of the beating cardiac myocytes were obtained, and the difference between the two was considered a "change" in the intracellular calcium concentrations in the cardiac cycles. These data were compared among the groups.

\section{Statistical analysis}

All of the data were expressed as the mean \pm SD. Student's $t$-test was used to determine the significant differences between two groups, and a one-way ANOVA was used to evaluate three or more groups. Excel and the Graph Pad Prism 5 programs were used for the statistical analysis, and a value of $P<0.05$ was considered significant.

\section{Results}

\section{An increase in constrictive force}

Phe was added successively (3, 30, and $300 \mathrm{nmol} / \mathrm{L})$ to induce constriction in the pulmonary arterial rings of the normal and hypoxic groups, and the increase in the developed force was significant $(P<0.01)$ in the hypoxic group in Exp 1 and 2 compared with the normal group (Figure 1A-1D). Hypoxia exposure clearly enhanced the constrictive force of the pulmonary arterial rings, thereby increasing vascular resistance in the pulmonary arterial system. The increased vascular resistance caused hypoxia pulmonary artery hypertension. The abnormal increase in the vasocontractile force was reduced $(P<0.01)$ by APO, Nif, and RS (Figure 1). RS did not affect the constrictive activity of the normal pulmonary arterial rings.

\section{Impaired endothelium-dependent relaxation}

After the vasoconstriction caused by Phe reached a plateau, ACh was added successively $(0.01,0.1,1$, and $10 \mu \mathrm{mol} / \mathrm{L})$ to relax the pulmonary arterial rings. The endothelium-related vasodilatation was significantly compromised $(P<0.01)$ in the hypoxic rats compared to the normal rats and was significantly alleviated by APO, Nif, and RS in Exp 1 and 2 (Figure 2). In contrast, following the addition of SNP $10 \mu \mathrm{mol} / \mathrm{L}$, the vasorelaxation of vascular smooth muscle was dilated directly and was not impaired in the hypoxic group; therefore, no difference was found among the groups. RS did not cause an increase in the ACh-induced vasorelaxation in normal rats.

\section{Reduced NO bioavailability and maximal NO release}

The NO bioavailability was evaluated by vascular activity assessment of the pulmonary arterial rings using two procedures. First, the constrictive responses to three concentrations of Phe were monitored, and the AUC (area under the curve) of the vasoconstrictive force was calculated. Second, the AUC was estimated again after L-NA, an inhibitor for eNOS, was added in a separate experiment. The difference of the AUC in the presence and absence of L-NA represents the NO bio- 

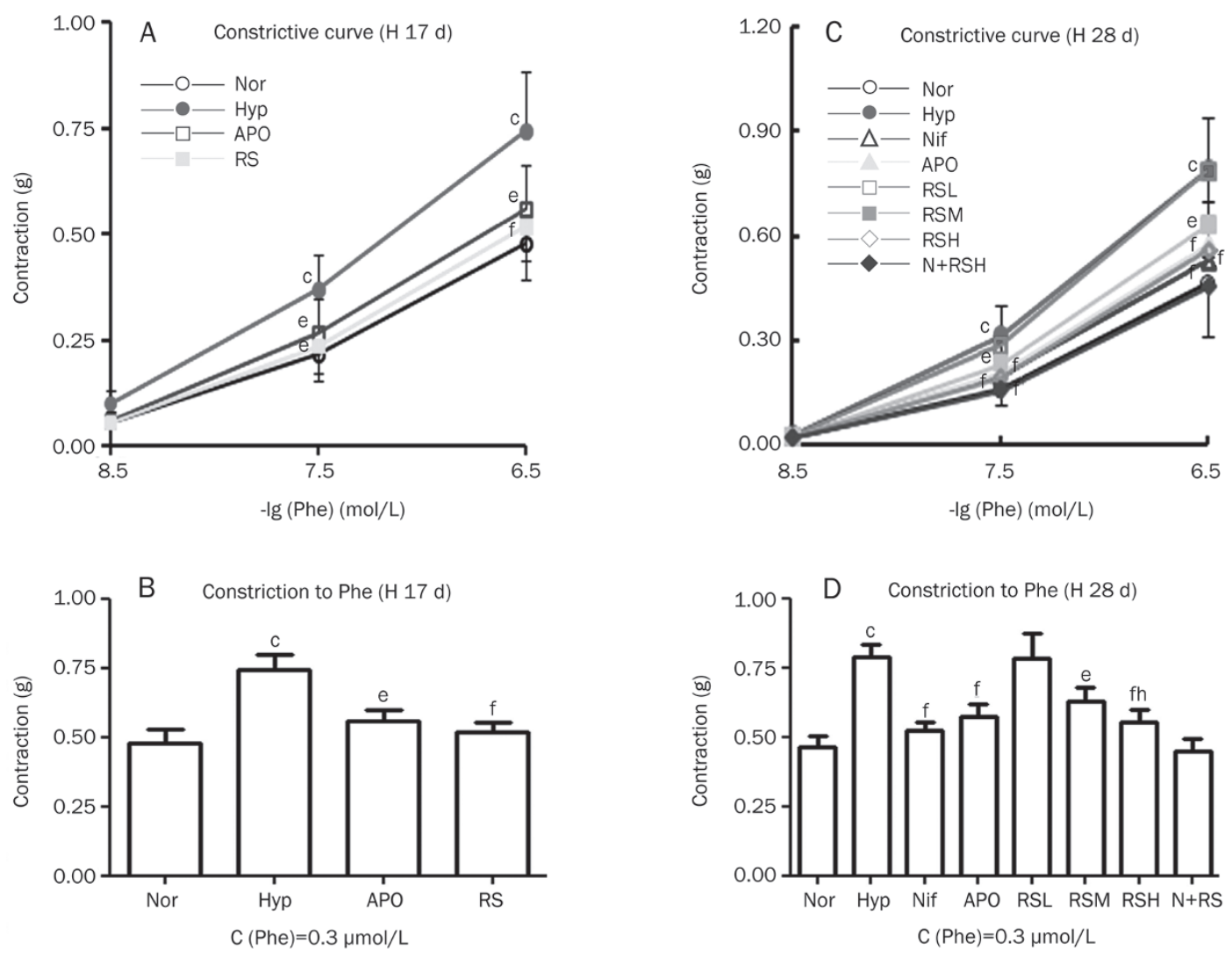

Figure 1. Vascular constrictive activity was increased in the hypoxic pulmonary artery and was alleviated by APO (apocynin), Nif (nifedipine), and RS (CPU86017-RS), respectively. (A, B) Hypoxia for 17 d (H 17 d), ( $n=6)$. Nor-normal (०), Hyp-hypoxia (•), APO (apocynin, 80 mg/kg, po) ( $\square$ ), RS (RS 80 mg/

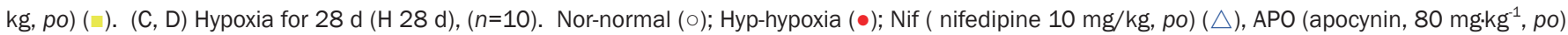

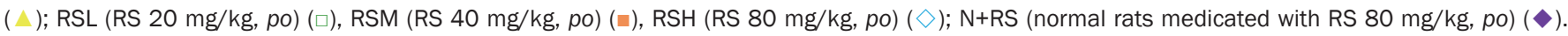
Mean \pm SD. $n=6-10 .{ }^{b} P<0.05,{ }^{c} P<0.01$ vs Nor. ${ }^{\mathrm{e}} P<0.05,{ }^{\mathrm{f}} P<0.01$ vs Hyp. ${ }^{\mathrm{h}} P<0.05$ vs RSL.

availability: the larger the difference between the two AUC values, the higher the NO availability in the tested artery. The increased constrictive force of the hypoxic pulmonary artery rings in the absence of L-NA was due to reduced NO availability in the pulmonary artery, and a smaller increase in the contractile force was observed while L-NA was added. NO bioavailability was decreased significantly in the Hyp group $(P<0.01$ vs Nor) in these two experiments and was remarkably increased $(P<0.01$ vs Hyp) after APO and RS interventions. RS did affect the NO bioavailability of the normal group $(P>0.05)$ (Figure 3A, 3C).

Both in Exp 1 and 2, the maximal NO release was decreased significantly in the Hyp group $(P<0.01)$ compared with Nor and a significant recovery in the NO release was found after $\mathrm{APO}$ and RS interventions $(P<0.01$ vs Hyp). RS had no effects on the maximum NO release of the normal group $(P>0.05)$ (Figure 3B, 3D).

\section{Remodeling of the pulmonary arterioles}

Changes in vascular activity are always associated with a morphological remodeling of the pulmonary vasculature; therefore, the changes in the thickness of vascular smooth muscle in the pulmonary arteriole were examined. A wall thickness
(WT) of the pulmonary arterioles less than $150 \mu \mathrm{m}$ in diameter was evaluated in Exp 1 and 2, and a remodeling of the vasculature, characterized as increased vascular wall thickness, was significant $(P<0.01)$ in the hypoxic rats when compared with the normal rats in $\operatorname{Exp} 2$ (Figure 4A). Similar data from Exp 1 are not shown. Treatment with Nif, APO, and RS (20,40, and $80 \mathrm{mg} / \mathrm{kg}$ ) attenuated the pulmonary arteriole remodeling compared to the Hyp group. The reduction of the arteriolar vasculature thickness by RS occurred in a dose-dependent manner, and the RS $80 \mathrm{mg} / \mathrm{kg}$ alone did not affect the WT of the pulmonary arterioles in the normal rats (Figure 4A, 6).

\section{Suppression of increased ROS in cultured cardiac cells}

ROS generation was enhanced in the cardiac myocytes incubated with $\mathrm{H}_{2} \mathrm{O}_{2}$, which was suspected to activate NADPH oxidase in the myocytes. Accordingly, we added APO to the medium to determine whether APO could suppress the ROS generation, as labeled with DHE fluorescence in the cardiac cells; we also addressed whether direct evidence of ROSsuppressing activity for RS could be found. Hypoxia damages cells mainly by increasing ROS generation; therefore, isolated cardiac cells of neonate rats were cultured with $\mathrm{H}_{2} \mathrm{O}_{2}$ $(10 \mu \mathrm{mol} / \mathrm{L})$, which mimics the injury from hypoxia exposure. 

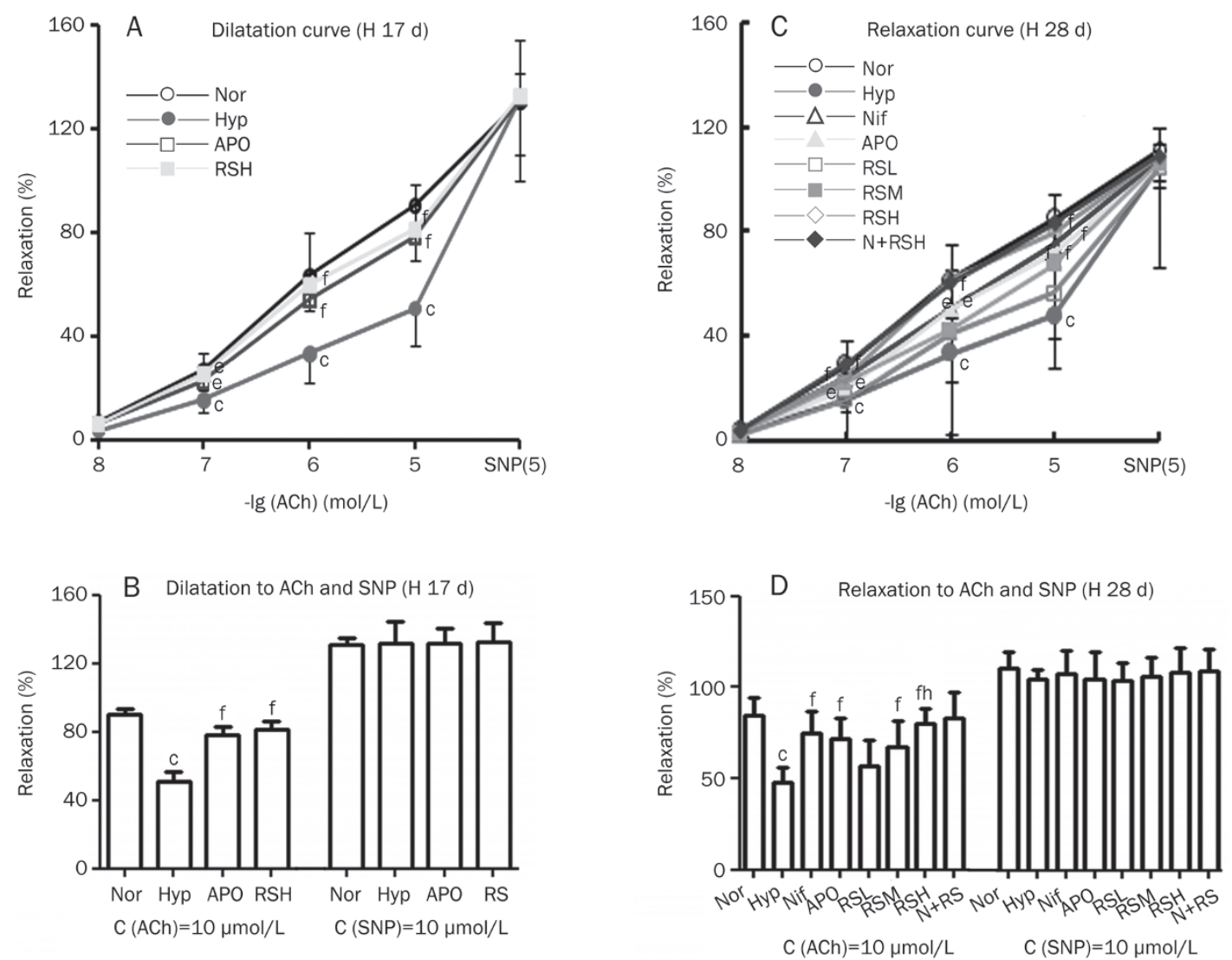

Figure 2. Vascular dilative activity was reduced in the hypoxic pulmonary artery and was alleviated by Nif, APO, and RS, respectively. (A, B) Hypoxia for

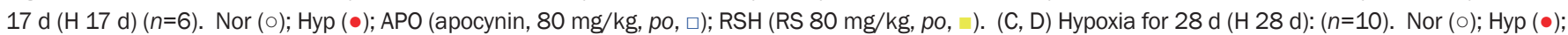
Nif (nifedipine $10 \mathrm{mg} / \mathrm{kg}$, po, $\triangle$ ); APO (apocynin, $80 \mathrm{mg} / \mathrm{kg}$, po, $\triangle$ ); RSL (RS $20 \mathrm{mg} / \mathrm{kg}$, po, 口); RSM (RS $40 \mathrm{mg} / \mathrm{kg}, \mathrm{po}$, ш); RSH (RS $80 \mathrm{mg} / \mathrm{kg}, p 0, \diamond$ ); $\mathrm{N}+\mathrm{RS}$ (normal rats medicated with RS $80 \mathrm{mg} / \mathrm{kg}, p o$, ). Mean \pm SD. $n=6-10 .{ }^{\mathrm{b}} P<0.05,{ }^{\mathrm{c}} P<0.01$ vs Nor. ${ }^{\mathrm{e}} P<0.05,{ }^{\mathrm{f}} P<0.01 \mathrm{vs}$ Hyp. ${ }^{\mathrm{h}} P<0.05$ vs RSL.

The fluorescence was significantly exaggerated in the $\mathrm{H}_{2} \mathrm{O}_{2}$ group $(P<0.01)$, as compared with the normal group, and the exaggerated ROS generation was significantly suppressed $(P<0.01)$ by APO, an inhibitor of NADPH oxidase. Interestingly, the beneficial effects of Nif were also significant. The suppressive effects of RS on ROS generation were positive and comparable to those of APO and Nif (Figure 4B, 6B).

\section{Suppression of intracellular $\left[\mathrm{Ca}^{2+}\right]_{\mathrm{i}}$}

To evaluate the suppression of $\left[\mathrm{Ca}^{2+}\right]_{i}$ by APO and RS, the isolated primary cardiac myocytes were cultured with $\mathrm{H}_{2} \mathrm{O}_{2}$ to mimic hypoxia injury. An abnormal increase of $\left[\mathrm{Ca}^{2+}\right]_{\mathrm{i}}$ was found in the beating cardiac myocytes with Hyp (hypoxia that was mimicked by adding $\mathrm{H}_{2} \mathrm{O}_{2}, P<0.01$ ), as compared with the normal group). The systolic and diastolic values and their changes were significantly enhanced after exposure to $\mathrm{H}_{2} \mathrm{O}_{2}$, highlighting the likely involvement of an increase in the intracellular calcium in hypoxic pulmonary arteries. The abnormal increase of intracellular calcium was greatly reduced $(P<0.01)$ by the intervention with Nif; however, the effects were reproduced by an NADPH oxidase blocker, APO. RS was found to reduce the enhanced $\left[\mathrm{Ca}^{2+}\right]_{\mathrm{i}}$ caused by hypoxia, which was comparable to that of Nif and APO (Figure 4C, 5, 6C).

\section{Discussion}

We reported previously that the pulmonary artery is more sensitive to hypoxia than the systemic circulation ${ }^{[22]}$. Chronic hypoxia exaggerates the production of ROS, which likely occurs in multiple steps. ROS are primarily produced from the abnormal electron transport in the mitochondria, and the produced ROS in turn stimulate NADPH oxidase to cause further and sustained ROS production (Figure 7). An excessive production of ET-1, a causal factor contributing to pulmonary hypertension, is stimulated by ROS; in fact, $\mathrm{ET}_{\mathrm{A}}$ and $\mathrm{ET}_{\mathrm{B}}$ receptors are actively implicated in the pulmonary hypertension caused by either hypoxia ${ }^{[7,9]}$ or the inflammatory substance, monocrotalin ${ }^{[8,23]}$. Emerging data suggest that endothelin receptor antagonists, either selective $\mathrm{ET}_{\mathrm{A}}$ blockers or dual $\mathrm{ET}_{\mathrm{A}}$ and $\mathrm{ET}_{\mathrm{B}}$ blockers, successfully alleviate pulmonary hypertension in both experimental animals and clinical settings ${ }^{[23,24]}$. Therefore, ET-1 has been considered the most important factor affecting the pulmonary arterial system and critically impairs vascular activity. In addition, potent vasoconstrictive activity, $e g$, an activated $\mathrm{ET}_{\mathrm{A}}$, reduces the $\mathrm{NO}$ bioavailability and maxi- 

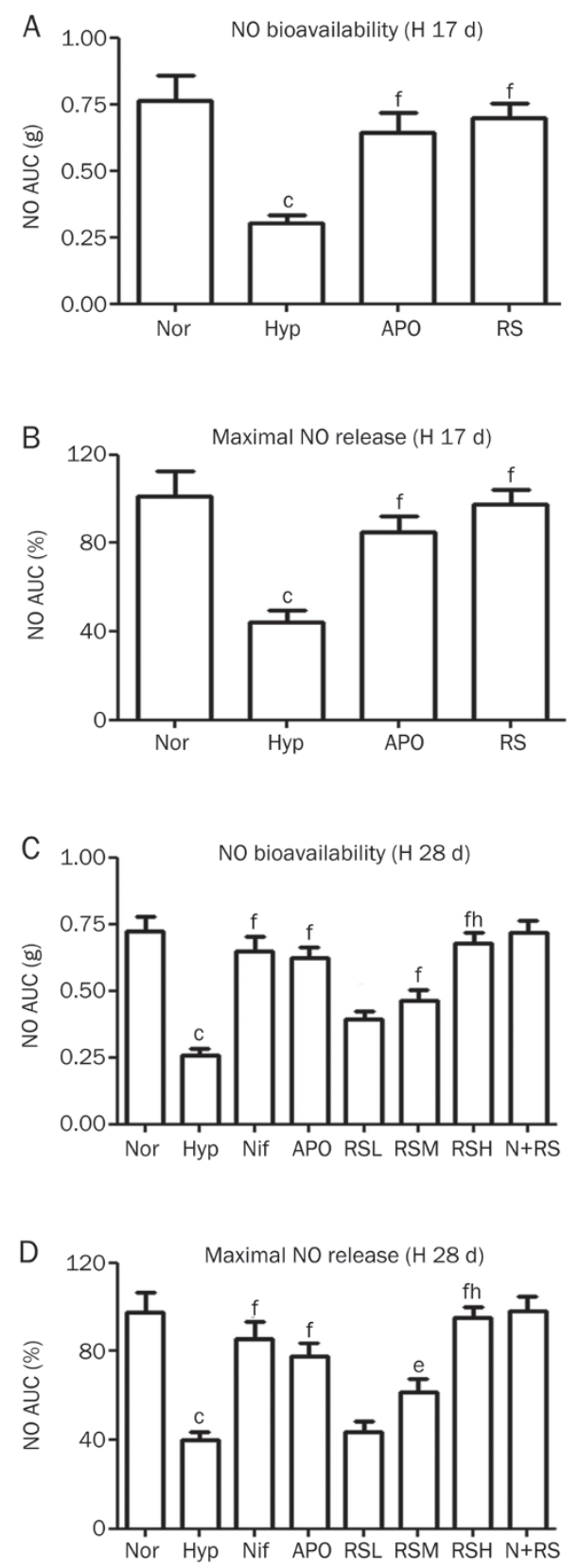

Figure 3. NO bioavailability and maximum NO release estimated functionally were reduced in hypoxic rats, in A, B (Exp 1) and C, D (Exp 2). Interventions with Nif, APO, and RS alleviated these changes significantly. Nor (Normal); Hyp (hypoxia); APO (apocynin, $80 \mathrm{mg} / \mathrm{kg}$, po); RSH (RS 80 $\mathrm{mg} / \mathrm{kg}, \mathrm{po})$. (C, D) Hypoxia for $28 \mathrm{~d}$ (H $28 \mathrm{~d}$ ): $(n=10)$. Nor (Normal); Hyp (Hypoxia); Nif (nifedipine $10 \mathrm{mg} / \mathrm{kg}$, po); APO (apocynin, $80 \mathrm{mg} / \mathrm{kg}, \mathrm{po}$ ); RSL (RS $20 \mathrm{mg} / \mathrm{kg}, p o$ ); RSM (RS $40 \mathrm{mg} / \mathrm{kg}, p o$ ); RSH (RS $80 \mathrm{mg} / \mathrm{kg}, p o$ ); $\mathrm{N}+\mathrm{RS}$ (normal rats medicated with RS $80 \mathrm{mg} / \mathrm{kg}, p o$ ). Mean \pm SD. $n=6$ 10. ${ }^{\mathrm{c}} P<0.01$ vs Nor. ${ }^{\mathrm{e}} P<0.05,{ }^{\mathrm{f}} P<0.01$ vs Hyp. ${ }^{\mathrm{h}} P<0.05$ vs RSL.

mal NO release from the vascular endothelium, thus exacerbating vascular resistance and remodeling in pulmonary circulation.

The bioactivity of ET-1 is at least in part mediated by $\mathrm{NADPH}$ oxidase, these including positive inotropism in the heart and an elevated $\left[\mathrm{Ca}^{2+}\right]_{\mathrm{i}}$, which is due to an increased frequency of open individual L-type channels; therefore, increased calcium influx is a consequence of the activation of $\mathrm{ET}_{\mathrm{A}}$, and the activation of L-type channels by $\mathrm{ET}_{\mathrm{A}}$ is mediated by the activation of NADPH oxidase ${ }^{[25,26]}$ (Figure 7).

Activated NADPH oxidase is the main source of ROS production, which is evidenced by the appearance of vascular abnormalities upon exposure to intermittent hypoxia and $\mathrm{H}_{2} \mathrm{O}_{2}$-induced ROS and an increase in the intracellular calcium in cardiomyocytes. NADPH oxidase as an important source of excessive ROS production, providing insight into many diseases, including diabetic nephropathy and cardiomyopathy and pulmonary hypertension ${ }^{[27-29]}$. In general, an activated $\mathrm{NADPH}$ oxidase produces ROS under hypoxic conditions; conversely, ROS serve as important inducers of ET-1, angiotensin, and tumor necrosis factor a, which stimulate NADPH oxidase. Our data are in agreement with our previous report that NADPH oxidase is an important source of ROS production in cardiac fibroblasts ${ }^{[5]}$.

The calcium balance in the pulmonary vascular cells critically modulates the vasoactivity of the pulmonary artery, and an increase in $\left[\mathrm{Ca}^{2+}\right]_{\mathrm{i}}$ allows an increase in the vascular tone responding to vasoconstrictive agents. An intracellular release of calcium from RyRs (ryanodine receptors) in vascular smooth muscles ${ }^{[30]}$ occurs in response to calcium influx through L-type channels, which is exacerbated by an enhanced influx of calcium, resulting in an increase in $\left[\mathrm{Ca}^{2+}\right]_{\mathrm{i}}$ in the systolic and diastolic cycles. However, it has been reported that the removal of extracellular $\mathrm{Ca}^{2+}$ may not affect the $\mathrm{H}_{2} \mathrm{O}_{2-}$ induced increase in $\left[\mathrm{Ca}^{2+}\right]_{i}^{[18]}$, indicating that a direct effect of stimulating intracellular $\mathrm{Ca}^{2+}$ release could be involved. In the present study, the application of nifedipine, which inhibits calcium influx, was expected to suppress the increased calcium levels by limiting the calcium ions transporting into the cells. L-type calcium channel activation by $\mathrm{H}_{2} \mathrm{O}_{2}$ (ROS) often follows hypoxemia after the exposure to intermittent hypoxia. In the present study, the increased calcium influx was suppressed by nifedipine and attenuated by the inhibition of NADPH oxidase. We provide direct evidence demonstrating that an activation of NADPH oxidase is also involved in exacerbated calcium influx; thus, by suppressing NADPH oxidase, apocynin treatment leads to a reduction in $\left[\mathrm{Ca}^{2+}\right]_{\mathrm{i}}$ in the cardiac myocytes. Therefore, as measured by an increase in ROS generation, we provide evidence that the activity of NADPH oxidase is linked to significant calcium influx, implying that a decline in $\left[\mathrm{Ca}^{2+}\right]_{i}$ reduces ROS generation, thus preventing the activation of NADPH oxidase under hypoxia ${ }^{[31]}$. The NADPH oxidase blocker apocynin sufficiently normalizes the exaggerated intracellular calcium in cardiomyocytes. We emphasize that NADPH oxidase modulates the free calcium levels in cardiac myocytes and, thus, participates in the pathogenesis of the cardiomyopathy caused by hypoxemia and contributes to hypoxic pulmonary hypertension (Figure 7).

In conclusion, abnormal vascular activity and the remodeling of pulmonary arterioles are due to the activation of NADPH oxidase under hypoxia, which is linked to activated 
A
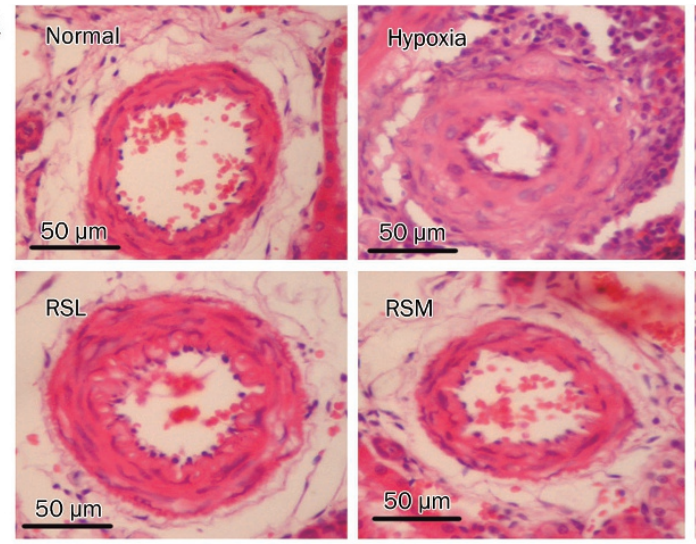

B
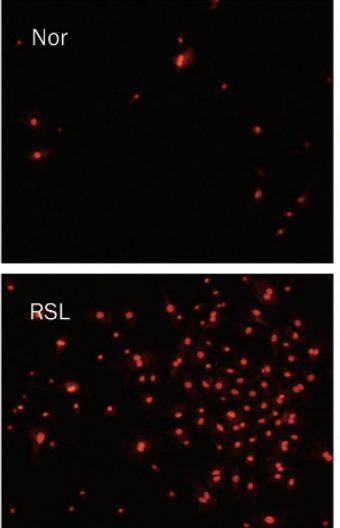

C
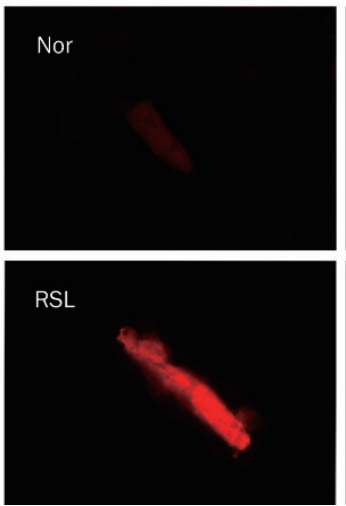
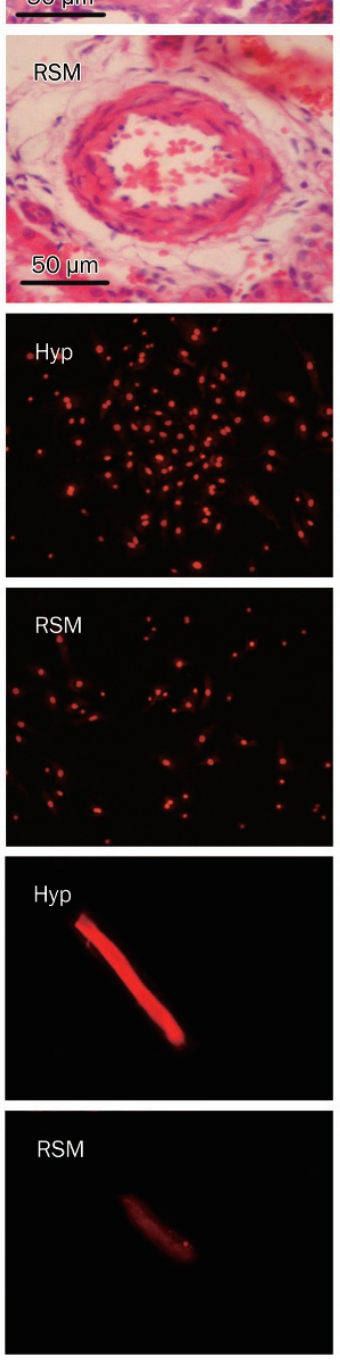
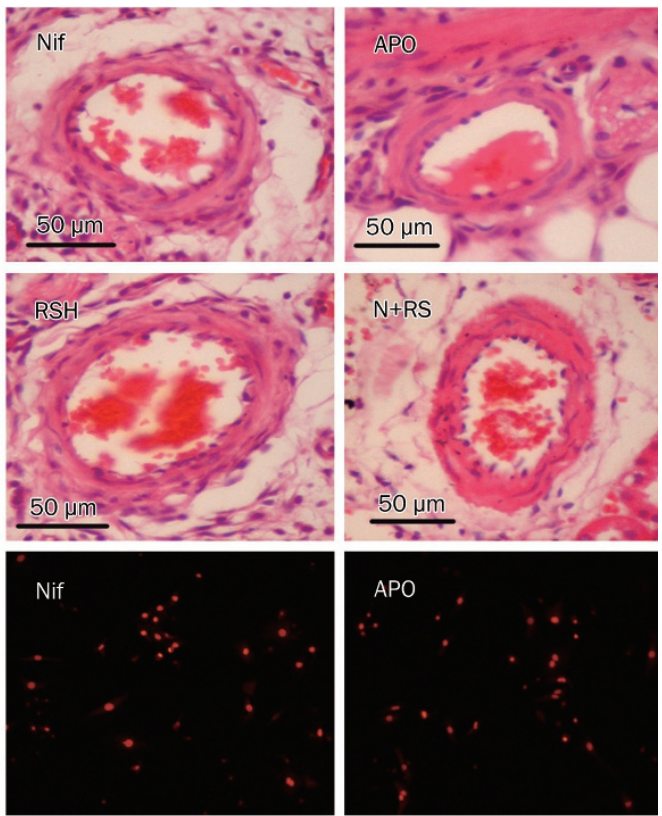

RSH

APO
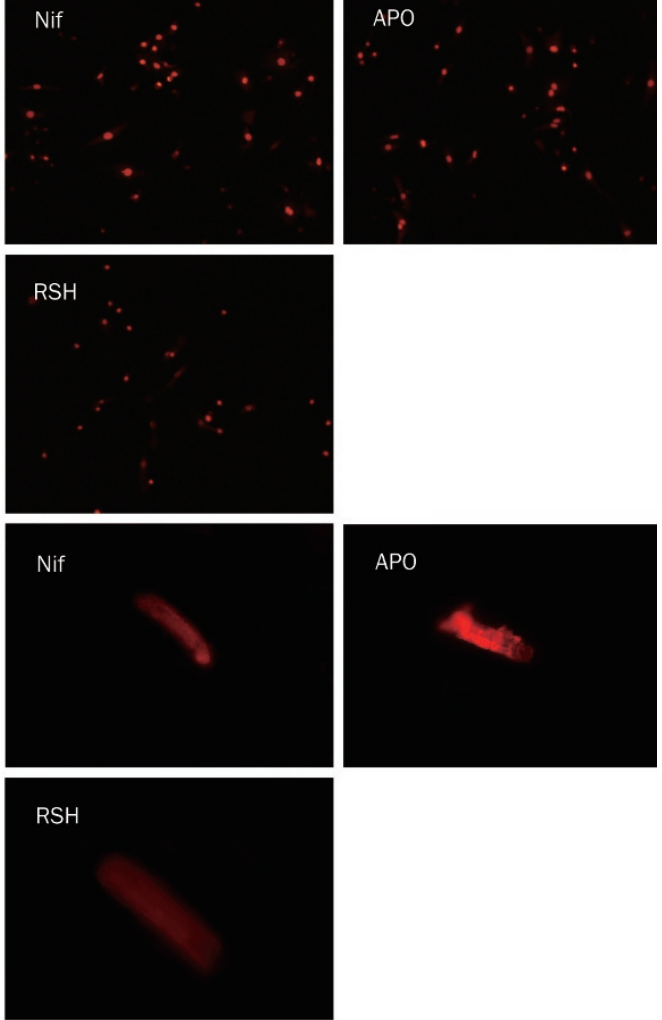

Figure 4. Histological changes of pulmonary arteriolar vascular wall $(A)$, the fluorescent images of DHE for ROS in cardiac cells (B), and the levels of $\left[\mathrm{Ca}^{2+}\right]_{i}$ in cardiac cells $(\mathrm{C})$ were compared. (A) Histological changes of the pulmonary arterioles with external diameter $<150 \mu \mathrm{m}$ (HE staining, ×400). Nor (Normal); Hyp (Hypoxia); Nif (nifedipine $10 \mathrm{mg} / \mathrm{kg}$, po); APO (apocynin, $80 \mathrm{mg} / \mathrm{kg}, p o$ ); RSL (RS 20 mg/kg, po); RSM (RS 40 mg/kg, po); RSH (RS 80 $\mathrm{mg} / \mathrm{kg}, \mathrm{po}$ ); $\mathrm{N}+\mathrm{RS}$ (normal rats medicated with RS $80 \mathrm{mg} / \mathrm{kg}$, po). (B) The fluorescence of dihydroethidium (DHE, 10 $\mu \mathrm{mol} / \mathrm{L}$ ) in neonate rat cardiac myocytes (×100). Normal (Nor), Hypoxia (Hyp, $\left.\mathrm{H}_{2} \mathrm{O}_{2} 10 \mu \mathrm{mol} / \mathrm{L}\right)$, nifedipine (Nif, $0.1 \mu \mathrm{mol} / \mathrm{L}$ ), apocynin (APO, $10 \mu \mathrm{mol} / \mathrm{L}$ ), RSL (RS, $1 \mu \mathrm{mol} / \mathrm{L})$, RSM (RS, $3 \mu \mathrm{mol} / \mathrm{L}), \mathrm{RSH}$ (RS, 10 $\mu \mathrm{mol} / \mathrm{L}) .(\mathrm{C})$ The fluorescent images of intracellular calcium. Normal (Nor), Hypoxia (Hyp, $\left.\mathrm{H}_{2} \mathrm{O}_{2} 10 \mu \mathrm{mol} / \mathrm{L}\right)$, nifedipine (Nif, $0.1 \mu \mathrm{mol} / \mathrm{L}$ ), apocynin (APO, $10 \mu \mathrm{mol} / \mathrm{L}), \mathrm{RSL}$ (RS 0.1 $\mu \mathrm{mol} / \mathrm{L}), \mathrm{RSM}$ (RS $1 \mu \mathrm{mol} / \mathrm{L})$, RSH (RS, $10 \mu \mathrm{mol} / \mathrm{L})$.
$\mathrm{ET}_{\mathrm{A}}$ and a reduction in the bioavailability of NO. Exacerbation of the intracellular calcium levels by $\mathrm{H}_{2} \mathrm{O}_{2}$ to mimics injury due to hypoxia and can be blocked by apocynin, an inhibitor of NADPH oxidase. Therefore, the inhibition of NADPH oxidase attenuates both the abnormal pulmonary vascular activity and the increase in ROS generation in cardiac myocytes. These abnormalities are normalized by raisanberine, which presumably suppresses the calcium influx and inhibits NADPH oxidase in the pulmonary arteriole and cardiac cells, respectively.

\section{Acknowledgements}

This work was supported by National Key New Drug Innovation Program, the Ministry of Science and Technology of China, No: 2009ZXJ09004-070 and The National Natural Science Foundation of China № $: 81070145$.

\section{Author contribution}

Jie GAO conducted the project and prepared the manuscript. $\mathrm{Yu}$-si CHENG assisted in performing the cellular experiments. Guo-lin ZHANG and Yi-qun TANG collected and processed data. Yin DAI supervised the experiments. Can ZHANG prepared and provided the tested compound. The project design, analyses of the results and revision of the manuscript were performed by De-zai DAI.

\section{References}

1 Hernandez-Rivera H, Martinez-Gonzalez H, Casal J, RodriguezOspina L. Pulmonary arterial hypertension: from pathophysiology to management. Bol Asoc Med P R 2011; 103: 34-40.

2 Yuan SH, Dai DZ, Guan L, Dai Y, Ji M. CPU0507, an endothelin receptor antagonist, improves rat hypoxic pulmonary artery hypertension and constriction in vivo and in vitro. Clin Exp Pharmacol Physiol 

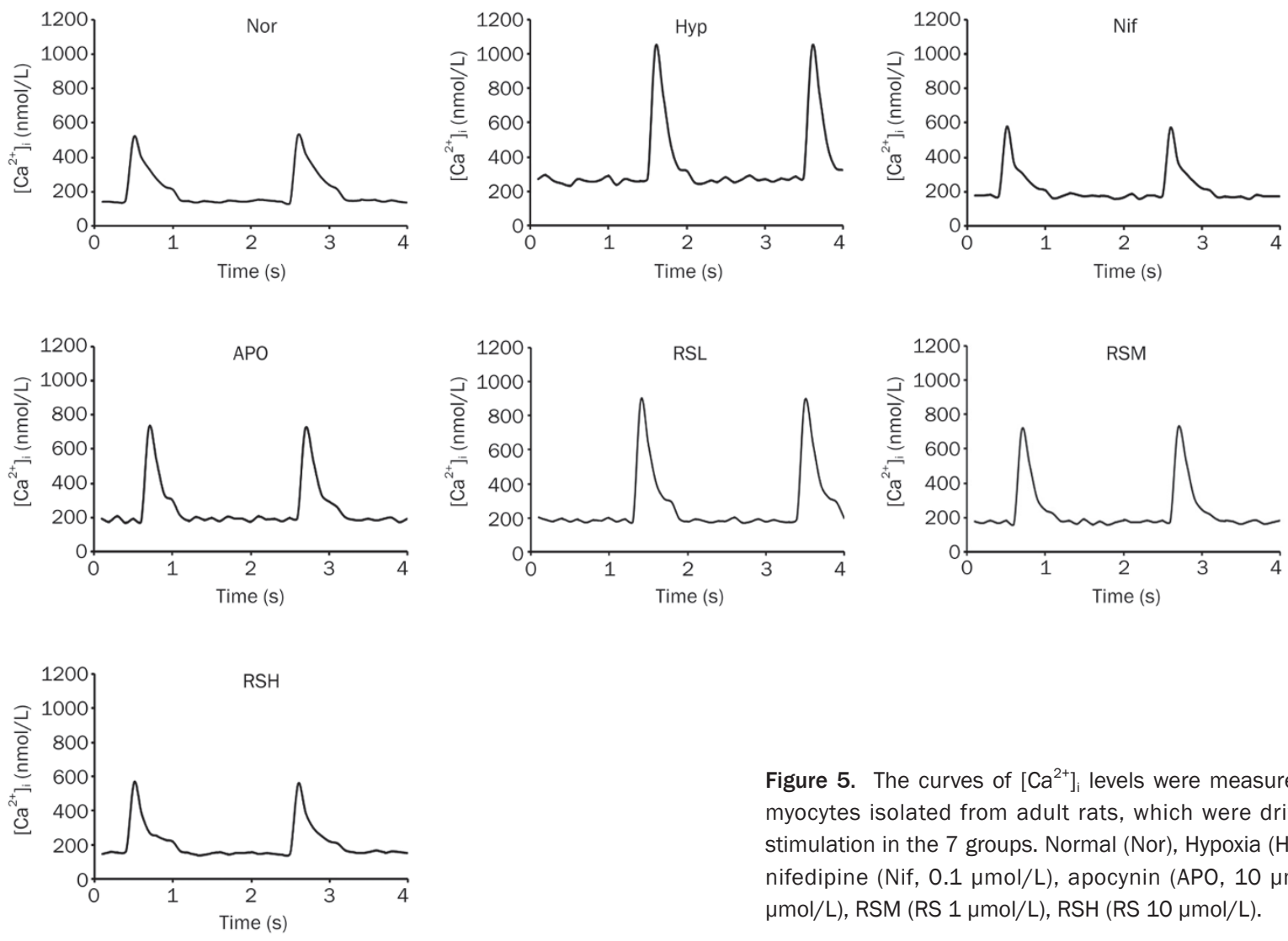

Figure 5. The curves of $\left[\mathrm{Ca}^{2+}\right]_{i}$ levels were measured in beating cardiomyocytes isolated from adult rats, which were driven by electric field stimulation in the 7 groups. Normal (Nor), Hypoxia (Hyp, $\mathrm{H}_{2} \mathrm{O}_{2} 10 \mu \mathrm{mol} / \mathrm{L}$ ), nifedipine (Nif, $0.1 \mu \mathrm{mol} / \mathrm{L}$ ), apocynin (APO, $10 \mu \mathrm{mol} / \mathrm{L}$ ), RSL (RS 0.1 $\mu \mathrm{mol} / \mathrm{L}$ ), RSM (RS $1 \mu \mathrm{mol} / \mathrm{L})$, RSH (RS $10 \mu \mathrm{mol} / \mathrm{L}$ ).
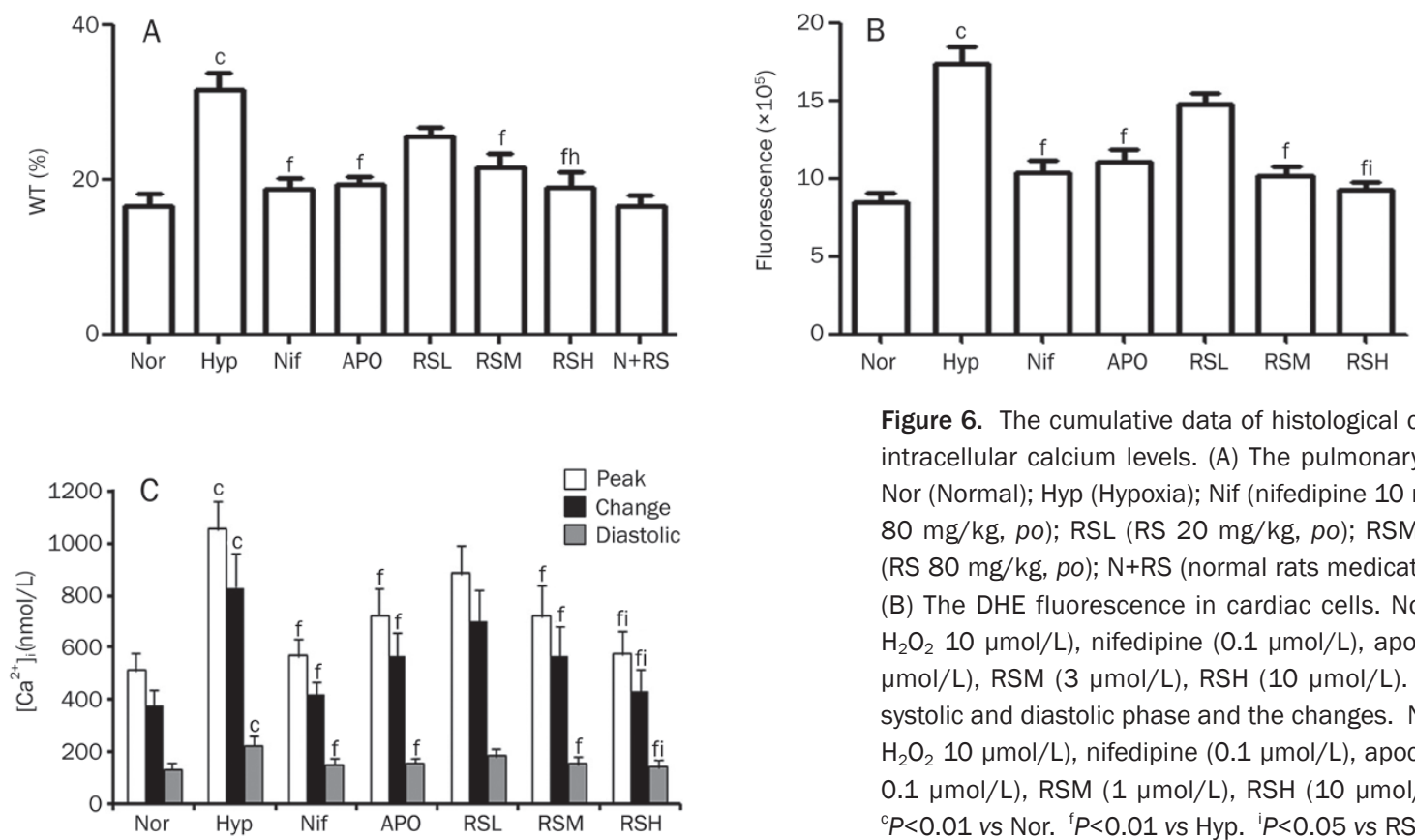

Figure 6. The cumulative data of histological changes, ROS genesis, and intracellular calcium levels. (A) The pulmonary arteriolar wall thickness. Nor (Normal); Hyp (Hypoxia); Nif (nifedipine $10 \mathrm{mg} / \mathrm{kg}$, po); APO (apocynin, $80 \mathrm{mg} / \mathrm{kg}, \mathrm{po}$ ); RSL (RS $20 \mathrm{mg} / \mathrm{kg}, p o$ ); RSM (RS $40 \mathrm{mg} / \mathrm{kg}, p o$ ); RSH (RS $80 \mathrm{mg} / \mathrm{kg}, p o$ ); N+RS (normal rats medicated with RS $80 \mathrm{mg} / \mathrm{kg}, p o$ ). (B) The DHE fluorescence in cardiac cells. Normal (Nor), Hypoxia (Hyp, $\left.\mathrm{H}_{2} \mathrm{O}_{2} 10 \mu \mathrm{mol} / \mathrm{L}\right)$, nifedipine $(0.1 \mu \mathrm{mol} / \mathrm{L})$, apocynin (10 $\left.\mu \mathrm{mol} / \mathrm{L}\right), \mathrm{RSL}(1$ $\mu \mathrm{mol} / \mathrm{L}), \operatorname{RSM}(3 \mu \mathrm{mol} / \mathrm{L}), \mathrm{RSH}(10 \mu \mathrm{mol} / \mathrm{L})$. (C) the levels of $\left[\mathrm{Ca}^{2+}\right]_{i}$ in systolic and diastolic phase and the changes. Normal (Nor), Hypoxia (Hyp, $\left.\mathrm{H}_{2} \mathrm{O}_{2} 10 \mu \mathrm{mol} / \mathrm{L}\right)$, nifedipine $(0.1 \mu \mathrm{mol} / \mathrm{L})$, apocynin $(10 \mu \mathrm{mol} / \mathrm{L}), \mathrm{RSL}$ (RS $0.1 \mu \mathrm{mol} / \mathrm{L})$, RSM $(1 \mu \mathrm{mol} / \mathrm{L}), \mathrm{RSH}(10 \mu \mathrm{mol} / \mathrm{L})$. Mean \pm SD. $n=6-10$. ${ }^{\mathrm{c}} P<0.01$ vs Nor. ${ }^{\mathrm{f}} P<0.01$ vs Hyp. ${ }^{\mathrm{i}} P<0.05$ vs RSL.

2006; 33: 1066-72.

3 Dupuis J, Hoeper MM. Endothelin receptor antagonists in pulmonary arterial hypertension. Eur Respir J 2008; 31: 407-15.

4 Chen CA, Wang TY, Varadharaj S, Reyes LA, Hemann C, Talukder MA, et al. S-glutathionylation uncouples eNOS and regulates its cellular and vascular function. Nature 2010; 468: 1115-8.
5 Peng HJ, Dai DZ, Ji H, Dai Y. The separate roles of endothelin receptors participate in remodeling of matrix metalloproteinase and connexin 43 of cardiac fibroblasts in maladaptive response to isoproterenol. Eur J Pharmacol 2010; 634: 101-6.

6 Dai DZ, Dai Y. Role of endothelin receptor A and NADPH oxidase in vascular abnormalities. Vasc Health Risk Manag 2010; 6: 787-94. 


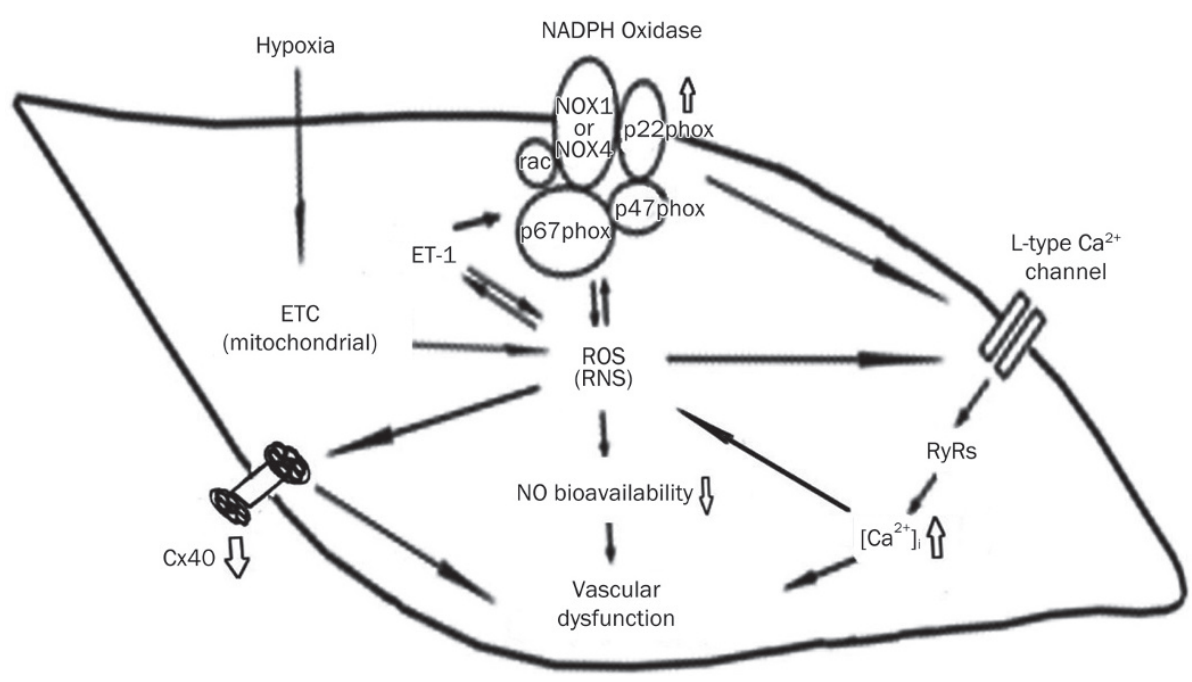

Figure 7. The mechanisms underlying the abnormal vascular activity in hypoxic pulmonary artery. Hypoxia promotes the genesis of ROS from the electron transport chain (ETC) at mitochondria, and thereafter, increases ET-1. ET-1 activates NADPH oxidase which contains catalytic (NOX1-4) and modulating subunits ( $\mathrm{p} 22^{\text {phox }}, \mathrm{p} 47^{\text {phox }}$, and $\mathrm{p} 67^{\text {phox }}$ ). An increased ROS stimulates the L-type $\mathrm{Ca}^{2+}$ channels to increase calcium influx and subsequent intracellular $\mathrm{Ca}^{2+}$ release from RyRs. Increased $\left[\mathrm{Ca}^{2+}\right]_{i}$ in turn stimulates the formation of ROS. ROS serves as an inducer for activating NADPH oxidase, therefore, blocking calcium influx is able to suppress NADPH oxidase. An increase in ET-1 and NADPH oxidase play key roles in the development of hypoxia pulmonary hypertension. A reduction in NO availability and release contributes to abnormal activity of hypoxic pulmonary artery. CPU86017-RS relieves hypoxic pulmonary arterial abnormality via blocking NADPH oxidase and calcium influx in the vasculature.

7 Cui B, Yu F, Dai DZ, Zhang TT, Tang XY, Dai Y. CPU0213, a novel endothelin receptor antagonist, relieves hypoxic pulmonary hypertension in rats by suppressing excessive ET-ROS pathway. Drug Dev Res 2007; 68: 42-52.

8 Zhang TT, Cui B, Dai DZ, Tang XY. Pharmacological efficacy of CPU 86017 on hypoxic pulmonary hypertension in rats: mediated by direct inhibition of calcium channels and antioxidant action, but indirect effects on the ET-1 pathway. J Cardiovasc Pharmacol 2005; 46: 727 34.

9 Li N, Dai D, Dai Y. CPU86017 and its isomers improve hypoxic pulmonary hypertension by attenuating increased $\mathrm{ET}_{\mathrm{A}}$ receptor expression and extracellular matrix accumulation. Naunyn-Schmiedeberg's Arch Pharmacol 2008; 378: 541-52.

10 Nisbet RE, Graves AS, Kleinhenz DJ, Rupnow HL, Reed AL, Fan TH, et al. The role of NADPH oxidase in chronic intermittent hypoxia-induced pulmonary hypertension in mice. Am J Respir Cell Mol Biol 2009; 40: 601-9.

11 Selemidis S, Sobey CG, Wingler K, Schmidt HH, Drummond GR. NADPH oxidases in the vasculature: molecular features, roles in disease and pharmacological inhibition. Pharmacol Ther 2008; 120 : 254-91.

12 Report. UAD, (Ed.) URDS. Research from the national institutes of Health, national Institute of diabetes and digestive kidney disease, and Charles R. Drew University of Medicine and Science High School Student Research Program - Summer 2005. Ethn Dis 2006; 16: 1-39.

13 Su W, Dai DZ, Liu HR, Na T, Dai Y. Upregulated endothelin system in diabetic vascular dysfunction and early retinopathy is reversed by CPU0213 and total triterpene acids from fructus corni. Clin Exp Pharmacol Physiol 2007; 34: 1228-33.

14 Li N, Jia N, Dai DZ, Dai Y. Endothelin receptor antagonist CPU0213 and vitamin E reverse downregulation of FKBP12.6 and SERCA2a: a role of hyperphosphorylation of PKCepsilon. Eur J Pharmacol 2008;
591: 211-8.

15 Qi MY, Feng Y, Dai DZ, Li N, Cheng YS, Dai Y. CPU86017, a berberine derivative, attenuates cardiac failure through normalizing calcium leakage and downregulated phospholamban and exerting antioxidant activity. Acta Pharmacol Sin 2010; 31: 165-74.

16 Zhang TT, Cui B, Dai DZ, Su W. CPU 86017, p-chlorobenzyltetrahyd roberberine chloride, attenuates monocrotaline-induced pulmonary hypertension by suppressing endothelin pathway. Acta Pharmacol Sin 2005; 26: 1309-16.

17 Li N, Yang L, Dai DZ, Wang QJ, Dai Y. Chiral separation of racemate CPU86017, an anti-arrhythmic agent, produces stereoisomers possessing favourable ion channel blockade and less alpha-adrenoceptor antagonism. Clin Exp Pharmacol Physiol 2008; 35: 643-50.

18 Luo L, Dai D, Cheng Y, Zhang Q, Yuan W, Dai Y. Sildenafil improves diabetic vascular activity through suppressing endothelin receptor $\mathrm{A}$, iNOS and NADPH oxidase which is comparable with the endothelin receptor antagonist CPU0213 in STZ-injected rats. J Pharm Pharmacol 2011; 63: 943-51.

19 Hu C, Yu F, Dai DZ, Dai Y. Stress-up-regulated myocardial endothelin receptors are suppressed by chlorobenzyltetrahydroberberine CPU86017 and its RS chiral isomer. J China Pharm Univ 2009; 40: 374-9.

20 Huang ZJ, Dai DZ, Li N, Na T, Ji M, Dai Y. Calcium antagonist property of CPU228, a dofetilide derivative, contributes to its low incidence of torsades de pointes in rabbits. Clin Exp Pharmacol Physiol 2007; 34: 310-7.

21 Mirza MA, Zhang XQ, Ahlers BA, Qureshi A, Carl LL, Song J, et al. Effects of phospholemman downregulation on contractility and $\left[\mathrm{Ca}^{2+}\right]$ i transients in adult rat cardiac myocytes. Am J Physiol Heart Circ Physiol 2004; 286: H1322-30.

22 Yuan SH, Li N, Dai DZ. The different vasomotor of pulmonary and tail arteries from two pulmonary hypertension rat models and in vitro drug intervention. Prog Pharm Sci 2006; 30: 314-21. 
23 Cui B, Cheng YS, Dai DZ, Li N, Zhang TT, Dai Y. CPU0213, a non-selective ETA/ETB receptor antagonist, improves pulmonary arteriolar remodeling of monocrotaline-induced pulmonary hypertension in rats. Clin Exp Pharmacol Physiol 2009; 36: 169-75.

24 Galiè N, Negro L, Simonneau G. The use of combination therapy in pulmonary arterial hypertension: new developments. Eur Respir Rev 2009; 18: 148-53.

25 De Giusti VC, Correa MV, Villa-Abrille MC, Beltrano C, Yeves AM, de Cingolani GE, et al. The positive inotropic effect of endothelin-1 is mediated by mitochondrial reactive oxygen species. Life Sci 2008; 83 : 264-71.

26 Zeng Q, Zhou Q, Yao F, O’Rourke ST, Sun C. Endothelin-1 regulates cardiac L-type calcium channels via $\mathrm{NAD}(\mathrm{P}) \mathrm{H}$ oxidase-derived superoxide. J Pharmacol Exp Ther 2008; 326: 732-8.

27 Xu J, Yu F, Dai DZ, Dai Y. High glucose-induced vascular dysfunction and expression of vascular ET_AR and OB-Rb: intervention effects of
ETR antagonist CPU0213. Prog Pharm Sci 2009; 3: 125-31.

28 Dennis KE, Aschner JL, Milatovic D, Schmidt JW, Aschner M, Kaplowitz MR, et al. NADPH oxidases and reactive oxygen species at different stages of chronic hypoxia-induced pulmonary hypertension in newborn piglets. Am J Physiol Lung Cell Mol Physiol 2009; 297: L596-607.

29 Sedeek M, Callera G, Montezano A, Gutsol A, Heitz F, Szyndralewiez C, et al. Critical role of Nox4-based NADPH oxidase in glucose-induced oxidative stress in the kidney: implications in type 2 diabetic nephropathy. Am J Physiol Renal Physiol 2010; 299: F1348-58.

30 Wang YX, Zheng YM. ROS-dependent signaling mechanisms for hypoxic $\mathrm{Ca}^{2+}$ responses in pulmonary artery myocytes. Antioxid Redox Signal 2010; 12: 611-23.

31 Amberg GC, Earley S, Glapa SA. Local regulation of arterial L-type calcium channels by reactive oxygen species. Circ Res 2010; 107 : 1002-10. 